\title{
POLICY ANAL \\ The Medical Home and Care Coordination in Disaster Recovery: Hypothesis for Interventions and Research
}

\author{
Robert K. Kanter, MD; David M. Abramson PhD, MPH; Irwin Redlener MD; \\ Delaney Gracy MD, MPH
}

\section{ABSTRACT}

In postdisaster settings, health care providers encounter secondary surges of unmet primary care and mental health needs that evolve throughout disaster recovery phases. Whatever a community's predisaster adequacy of health care, postdisaster gaps are similar to those of any underserved region. We hypothesize that existing practice and evidence supporting medical homes and care coordination in primary care for the underserved provide a favorable model for improving health in disrupted communities. Elements of medical home services can be offered by local or temporary providers from outside the region, working out of mobile clinics early in disaster recovery. As repairs and reconstruction proceed, local services are restored over weeks or years. Throughout recovery, major tasks include identifying high-risk patients relative to the disaster and underlying health conditions, assisting displaced families as they transition through housing locations, and tracking their evolving access to health care and community services as they are restored. Postdisaster sources of financial assistance for the disaster-exposed population are often temporary and evolving, requiring up-to-date information to cover costs of care until stable services and insurance coverage are restored. Evidence to support disaster recovery health care improvement will require research funding and metrics on structures, processes, and outcomes of the disaster recovery medical home and care coordination, based on adaptation of standard validated methods to crisis environments. (Disaster Med Public Health Preparedness. 2015;9:337-343)

Key Words: care coordination, case management, community disruption, disaster recovery, medical home

A fter the intensity of a disaster fades from the news, health care needs continue to exceed resources in a disrupted community. Community functions are interrupted for days or weeks. Then, services are gradually restored over months or years. ${ }^{1-3}$ In some cases, losses of services may have been overwhelming. For example, postHurricane Katrina flooding closed almost all of the health care infrastructure of New Orleans. Other disasters such as the 2011 tornado in Joplin, Missouri and Hurricane Sandy in New York and New Jersey damaged a substantial portion, but not all of the local hospitals and ambulatory care facilities. In still other major emergencies such as southwest wildfires, western floods, and accidents releasing toxic chemicals, populations were displaced and transportation was disrupted without substantial loss of health care infrastructure.

After disaster-related medical emergencies resolve, health care providers typically encounter a secondary surge of unmet primary care and mental health needs. ${ }^{3}$
Little evidence has been reported and no consensus is available to guide health care during the recovery phase after major community disruptions. We hypothesize that whatever the community's predisaster adequacy of health care, unmet primary care and mental health needs in a recovering community are similar to those for any underserved population. We propose that existing practice, policy, and research frameworks in primary care for the underserved may serve as favorable models for improving and evaluating health care in disrupted communities. Early restoration of medical homes and care coordination may be key solutions to meeting the secondary surge of needs in recovering communities. In support of these proposals, we review the concepts of medical homes and their associated services and detail evidence for medical home benefits for general populations, vulnerable populations, and especially underserved groups. Anecdotal evidence on postdisaster medical homes is presented. Funding, operational planning, and metrics must be developed in order to conduct research optimizing the medical home model for postdisaster health care. 


\section{THE MEDICAL HOME AND CARE COORDINATION IN ROUTINE PRIMARY CARE}

The medical home model provides a consistent team of multidisciplinary providers in partnership with patients and families, promoting access and continuity of care for adults ${ }^{4}$ and children. ${ }^{5}$ The medical home is accountable for all of the patient's health care needs, providing referrals to subspecialists and other community services when necessary, and coordinating the exchange and follow-up of medical information. Information technology with electronic records, ordering, and prescribing may facilitate the process. Access by phone, Internet, and telemedicine may supplement face-to-face appointments. Language and cultural differences are accommodated. Processes and interventions in the medical home are ideally evidencebased, and quality is promoted by ongoing monitoring of service utilization. Preliminary efforts have been made to integrate pharmacy ${ }^{6}$ and mental health services into medical home teams. National surveillance indicates that primary care medical home initiatives are rapidly expanding in the United States. ${ }^{7}$

Even for relatively healthy populations covered by health insurance and living in communities having comprehensive health care, navigating the complex network of services can be difficult. The more complex a patient's medical and psychosocial needs, the more assistance is needed to benefit from the complex network of the health care system. Care coordination is an essential component of medical home services promoting teamwork and continuity, and is especially important at the time of hospital discharge and other transitions in health status. Care coordinators, case managers, and patient navigators with professional backgrounds in nursing or social work have overlapping functions and may be considered as synonymous. In some organizations, training for individuals without a professional background may allow them to provide some aspects of the care coordination role. ${ }^{8}$ Existing models for care coordination include on-site services embedded within a clinical practice, ${ }^{9}$ or include a centralized service shared among multiple organizations. ${ }^{10}$ When the clinical team identifies a high-risk patient, coordinators collect interim information to anticipate needs in preparation for upcoming visits, facilitate patients getting to scheduled visits, contribute to the evaluation and health care plan at each visit, then match the patient's needs with ongoing care by the family, generalists and subspecialists, schools, and other community services. ${ }^{11,12}$ Care coordinators educate organizations as well as families about meeting a patient's needs. Assistance with insurance eligibility and other benefits, transportation, reminders of upcoming appointments, and translation for non-English speaking families all facilitate access to care. Coordinators also promote communication among services and agencies, and facilitate consents to share information.

\section{VULNERABLE AND UNDERSERVED POPULATIONS}

Vulnerable populations are at risk for adverse health consequences related to disadvantaged socioeconomic status, disabilities, health illiteracy, complex medical conditions or mental illness, young or elderly age, and language, cultural, and geographic barriers. For underserved populations, shortages of clinicians and pharmacies, and gaps in transportation, communication, information, and financial resources all limit access to health care. Regional factors may limit access to services for an entire population, or subpopulations may be underserved in areas with good general health care services. Undocumented immigrants and homeless families face particular obstacles in access to health care. For underserved populations, needs are unmet, leading to preventable morbidity. Vulnerable populations often lack access to services, and thus, suffer particularly severe health consequences.

\section{BENEFITS OF THE MEDICAL HOME FOR UNSELECTED, VULNERABLE, AND UNDERSERVED POPULATIONS}

For unselected populations of children, primary care in a medical home is more likely than other models to meet medical and dental needs. ${ }^{13}$ The medical home model reduces unmet needs for children with special health care needs, ${ }^{14}$ reduces serious illnesses and costs for children ${ }^{5,15-18}$ and adults $^{19,20}$ with special health care needs, improves biomarkers for adults with diabetes and hypertension, ${ }^{21}$ slows functional decline in the elderly, ${ }^{22}$ and reduces mortality in seniors. ${ }^{23}$ However, the lack of improvement in some process and outcome metrics ${ }^{24}$ and mixed results in cost savings relative to investments in these initiatives ${ }^{25}$ indicate that the medical home model requires continuing refinement.

The medical home approach is particularly important for underserved children. ${ }^{26,27}$ Care coordination improves the success of referrals to subspecialists for underserved families. ${ }^{28}$ School-based health centers provide an important resource to underserved adolescents. ${ }^{29}$ Most communities are underserved by mental health providers. Colocation of services by integrating mental health providers into the primary care medical home ${ }^{30}$ or homeless shelters ${ }^{31}$ improves access to mental and behavioral health care for children. For particularly disadvantaged populations, broader models of care coordination also include support for nutrition, employment, housing, and child care. ${ }^{32,33}$ Effective primary care interventions for disadvantaged children have health benefits that last into adulthood. ${ }^{34}$

\section{HEALTH CONDITIONS DURING DISASTER RECOVERY}

Disorders encountered during disaster recovery are similar to those in any primary care setting, ${ }^{35-40}$ whether the population is displaced or local services are disrupted. In children, these include asthma and seizures. Chronic pulmonary disease, diabetes, hypertension, and other cardiovascular diseases are common in adults. Minor trauma, mental health, and dental care are issues for all ages in disaster recovery. Displaced families face environmental hazards in shared temporary housing, including tobacco smoke, allergens, 
unsafe homes or neighborhoods, and behavioral issues associated with household crowding. Family injuries and deaths as well as interruptions of family routines intensify mental health disorders.

\section{COMMUNITY DISRUPTION CREATES AN UNDERSERVED POPULATION AND PREVENTABLE MORBIDITY}

After disaster-specific injuries and illnesses resolve, the disrupted community faces intensified needs associated with delayed services for primary care and mental health conditions. ${ }^{3,36,41}$ Medications and supplies may have been lost or become inaccessible. Medication replacement is difficult if prescribing information or providers are inaccessible, sources are disrupted, or costs are uncovered by insurance. Information losses include contact information for providers and insurance coverage. Access to primary and subspecialty care is often disrupted by damage to those services as well as by communication and transportation barriers. Loss of employment leads to loss of health insurance coverage. Unmet needs characterize an underserved population. Delays in access to primary care exacerbate ambulatory care sensitive conditions (ACSCs) as in any underserved community.

\section{DISASTER RECOVERY AND ANECDOTAL EXPERIENCE WITH THE MEDICAL HOME AND CARE COORDINATION}

If access, teamwork, and coordination are important on a normal day, medical home services are even more vital to promote access in a recovering community whose health care networks have been disrupted by a disaster. ${ }^{3,27,42}$ We propose the implementation of services that incorporate the medical home model immediately after the emergency phase of a disaster has resolved. Elements of medical home services can be offered by local or temporary providers from outside the region, working in mobile clinics early in disaster recovery. ${ }^{27,35,43}$ Locations of mobile facility deployment are specific to circumstances in each event. Mobile facilities supply refrigeration for medications and vaccines, as well as clinicians ready to provide immediate services until local facilities are repaired and local providers can cope with their own personal losses. Mobile services imported to a disaster zone from a remote location might be provided by a private organization that usually provides such services in its own community. This would require temporary reduction of services in the organization's home community in order to provide disaster relief. Alternatively, personnel, supplies, and equipment may be provided by Federal Disaster Medical Assistance Teams. Schools also provide a large set of resources for children capable of augmenting early disaster recovery services for pediatric primary care. ${ }^{26,44}$

Whatever the organization providing disaster relief, the medical home model may strengthen the response by providing care coordinators as members of the team at the earliest possible phase of the response. As in everyday primary care, care coordinators may have professional backgrounds in nursing or social work, or have special training in selected aspects of care coordination without a professional background.

Care coordination in normal circumstances requires knowledge of local services. After a disaster, local knowledge is even more important, as some services are destroyed, others displaced, and still others reopening at their original location after varying delays when repairs are completed. Care coordination in any circumstance facilitates transitions across settings, across changing needs, and in response to gaps in care. Transitions are amplified in disrupted communities. In addition to assisting displaced families as they transition through housing locations, a major task of the postdisaster care coordinator will be to track the evolving availability, contact information, and access by public transportation to health care and community services as they are restored. While providers and coordinators from outside areas may be helpful to temporarily increase the workforce, partnerships with local coordinators are important. When coordinators have been long-term residents from the involved community, it may be easier to develop trust and credibility with a stressed population. Community- and event-specific needs may be more understandable to local coordinators than to those provided by remote agencies.

For services lacking coordinators after disasters, it may be possible to temporarily share coordinators among multiple organizations. Alternatively, public agencies can provide care coordination services in partnership with private organizations or directly to individual families. ${ }^{45-49}$ Information about access to housing, health care, food and water, and transportation also may be provided by a "2-1-1" telephone service. $^{50}$

Postdisaster sources of financial assistance for the involved population and for organizations providing primary care are often temporary and evolving, requiring the care coordinator to maintain up-to-date information to cover costs of care until stable services and insurance coverage are restored. Postdisaster financial assistance for medical and mental health services, prescriptions, equipment, supplies, and child care have been supported by public and private grants. ${ }^{51-55}$ Financial barriers interfering with the restoration of primary care services have included a decline in health insurance coverage as a result of job loss in the disaster zone, shrinking population in the affected area, and competition for temporary disaster relief funding between local providers and organizations from outside the region. ${ }^{56}$ While postdisaster federal assistance is often available to nonprofit organizations, community health centers, and hospitals, private physician practices are less likely to receive such support. ${ }^{57}$

During the early phase of recovery, primary care clinical services are likely to be provided by physician generalists 
(primary care or emergency medicine) or supplemental providers (nurse practitioners and physician assistants) with a generalist background. Psychological first aid and screening for those needing specialized mental health care can be delivered by generalists. ${ }^{58}$ Colocated mental health and medical services were actively utilized in the mobile clinic model after Hurricane Katrina. ${ }^{38}$ As disaster recovery proceeds, local providers reopen primary care services in temporary or repaired settings, and later in definitive facilities, sometimes after very brief interruptions lasting only a few days. ${ }^{59}$ As resources become better organized with community recovery, service networks will be restored, typically evolving in a different configuration than before the disaster. ${ }^{52}$

\section{PRELIMINARY EVIDENCE FROM OBSERVATIONAL STUDIES OF OUTCOMES ASSOCIATED WITH DISASTER RECOVERY PRIMARY CARE}

One community's experience after a train derailment and chlorine gas spill forced an extended mass evacuation illustrates the importance of primary care in a disrupted community. ${ }^{60}$ Approximately 5400 residents were displaced from their homes for up to 2 weeks. Mental health and economic impacts of the accident lasted for years in an already economically disadvantaged community. Unmet primary care needs were assessed during a 36-month period prior to the accident and a 12-month postdisaster period, as measured by patients with ACSCs admitted to hospitals and emergency departments. ACSCs were identified by ICD-9 codes among adult Medicaid recipients. During the community recovery, the volume of primary care visits increased in an ambulatory care clinic, suggesting adequate primary care access. In contrast to the increase in primary care visits, hospital and emergency department ACSC admissions declined. Thus, secondary surge needs were adequately met by primary care services, with no increase in serious illness. However, medical home characteristics for primary care facilities were not described in the study.

Another test of the value of medical homes in postdisaster settings occurred in New Orleans, in which a safety net pediatric health clinic converted to a medical home with care coordination services, by coincidence, just prior to Hurricane Katrina in 2005. ${ }^{61}$ A nurse care coordinator identified specific needs of high-risk patients with complex medical conditions. Although community needs increased substantially after the storm, families reported significant improvement in 19 of 22 indicators. Improvements included physician accessibility, quality of physician-family communication, and physician familiarity and knowledge of the child's condition and family concerns. Assistance in coordinating with schools and parent support groups, and helping adolecents transition to adult services also improved. By the end of 2007, the care coordinator served a practice of 5146 patients, including 2064 children with special health care needs.

\section{EVIDENCE: NEXT STEPS}

Based on successes of medical homes in everyday primary care for general, vulnerable, and underserved populations, as well as preliminary experience with medical homes in disaster recovery, we hypothesize that medical home and care coordination services may be a favorable model for further development in disaster recovery health care. Limited experience with postdisaster medical homes and care coordination has been reported, but best practices have not been described in sufficient detail for other organizations to implement the structures and processes. The National Commission on Children and Disasters has endorsed disaster case management, ${ }^{62}$ but noted that evidence for its elements and methods as well as necessary funding remain inadequate. It is notable that only $6 \%$ of recently federally funded research on public health addressed improvements in performance of the health care system in disasters. ${ }^{63}$ If we are to advance health care in the aftermath of disasters, we need better evidence about what works (Table 1). The relationships between specific disaster recovery primary care interventions and health outcomes must become a focus of investigation.

First, funding is necessary to promote research on disaster recovery health care. A successful disaster recovery research program must be funded, designed, and ready for operational implementation before the public health emergency occurs.

\section{TABLE 1}

\section{Obtaining Evidence: Next Steps (adopted from Lurie et $\mathrm{al}^{70}$ )}

Ahead of time:

- Research grants promote a research infrastructure for investigation of health care in disaster recovery.

- Develop hypotheses on the relationship between medical home models for disaster recovery care and resulting health care processes and outcomes.

- Assemble collaborative teams of researchers, clinicians, health care organizational leaders, and communities to develop prototypes and a research process to implement and investigate disaster recovery health care.

- Adopt validated metrics for medical home structure, process, and outcome to the disaster recovery setting.

- Obtain regulatory approval by review boards for the protection of human subjects

After the disaster:

- Rapidly deploy teams, implement interventions, and collect data at the earliest stage of disaster recovery. 
Waiting to design the interventions and investigation until after the disaster ensures incomplete data collection, with loss of information on adverse exposures, risk factors, interventions, and outcomes. Lacking research grants to create a research infrastructure, disaster recovery experience will remain anecdotal. Engaging a recovering community in its health services is an important prerequisite to conducting successful scientific investigation in the postdisaster setting. ${ }^{64}$ Existing community organizations that assist individuals with disabilities and special health care needs may be important resources planning for disaster recovery health care and research. ${ }^{65}$ Circumstances of public health interventions seldom permit prospectively controlled trials of interventions. Thus, nonrandomized observational studies of interventions in disaster recovery health care must control for all observable adverse exposure, risk, and mitigation variables. Metrics to describe structures, processes, and outcomes of the disaster recovery medical home and care coordination must be based on standard validated methods for adults ${ }^{12}$ and children, ${ }^{66,67}$ including preliminary attempts to adapt these metrics in crisis environments. ${ }^{60,68}$ Poorly validated performance metrics may be inconsistent with patient priorities. ${ }^{69}$

If disaster recovery medical homes and care coordination have the potential to improve health in recovering communities, experience will emerge from organizations with prototype programs. Sound operational structures will contribute to effective practices. Effective services will contribute to good outcomes. Hypothesis-driven studies must determine whether programs that have shown benefit in underserved populations will also help disrupted communities recovering from disasters.

\section{About the Authors}

National Center for Disaster Preparedness, Earth Institute, Columbia University, New York, NY (Drs Kanter, Abramson, and Redlener); Virginia Tech Carilion School of Medicine, Roanoke, Va, and SUNY Upstate Medical University, Syracuse, NY (Dr Kanter); New York University, NY, NY (Dr Abramson); and Children's Health Fund, New York, NY (Drs Redlener and Gracy).

Correspondence and reprint requests to Robert K. Kanter, MD, National Center for Disaster Preparedness, Earth Institute, Columbia University, 215 W 125th St, 3rd floor, NY, NY 10027 (e-mail: rkk2117@columbia.edu).

\section{Funding and Support}

The study was supported by a grant from the Baton Rouge Area Foundation, CU13-0598.

Published online: June 5, 2015.

\section{REFERENCES}

1. Abramson D, Peek L, Redlener I, et al. Children's Health after the Oil Spill: a Four-State Study. Findings from the Gulf Coast Population Impact (GCPI) Project. (NCDP Briefing Report 2013_1). Columbia University Academic Commons. http://academiccommons.columbia. edu/item/ac:156715. Published 2013. Accessed December 17, 2013.

2. Alesch DJ, Arendt LA, Holly JN. Managing for Long Term Community Recovery in the Aftermath of Disaster. Fairfax, Va: Public Entity Risk Institute; 2009.
3. Runkle JD, Brock-Martin A, Karmaus W, et al. Secondary surge capacity: a framework for understanding long-term access to primary care for medically vulnerable populations in disaster recovery. Am J Public Health. 2012;102:e24-e32.

4. Jackson GL, Powers BJ, Chatterjee R, et al. The patient-centered medical home. Ann Intern Med. 2013;158:169.

5. Mosquera RA, Avritscher EB, Samuels CL, et al. Effect of an enhanced medical home on serious illness and cost of care among high-risk children with chronic illness: a randomized clinical trial. JAMA. 2014;312: 2640-2648.

6. Patterson BJ, Solimeo SL, Stewart KR, et al. Perceptions of pharmacists' integration into patient-centered medical home teams. Res Social Adm Pharm. 2015;11:85-95.

7. Edwards ST, Bitton A, Hong J, et al. Patient-centered medical home initiatives expanded in 2009-13: providers, patients, and payment incentives increased. Health Aff (Millwood). 2014;33: 1823-1831.

8. Hedlund N, Risendal BC, Pauls H, et al. Dissemination of patient navigation programs across the United States. J Public Health Manag Pract. 2014;20:e15-e29.

9. Hines P, Mercury M. Designing the role of the embedded care manager. Prof Case Manag. 2013;18:182-187.

10. Abrams M, Schor EL, Schoenbaum S. How physician practices could share personnel and resources to support medical homes. Health Aff (Millwood). 2010;29:1194-1199.

11. McAllister JW, Presler E, Cooley WC. Practice-based care coordination: a medical home essential. Pediatrics. 2007;120:e723-e733.

12. Schultz EM, Pineda N, Lonhart J, et al. A systematic review of the care coordination measurement landscape. BMC Health Serv Res. 2013;13:119.

13. Strickland BB, Jones JR, Ghandour RM, et al. The medical home: health care access and impact for children and youth in the United States. Pediatrics. 2011;127:604-611.

14. Boudreau AA, Perrin JM, Goodman E, et al. Care coordination and unmet specialty care among children with special healthcare needs. Pediatrics. 2014;133:1046-1053.

15. Klitzner TS, Rabbitt LA, Chang RK. Benefits of care coordination for children with complex disease: a pilot medical home project in a resident teaching clinic. J Pediatr. 2010;156:1006-1010.

16. Cooley WC, McAllister JW, Sherrieb K, et al. Improved outcomes associated with medical home implementation in pediatric primary care. Pediatrics. 2009;124:358-364.

17. Bergert L, Patel SJ, Kimata C, et al. Linking patient-centered medical home and asthma measures reduces hospital readmission rates. Pediatrics. 2014;134:e249-e256.

18. Antonelli RC, Stille CJ, Antonelli DM. Care coordination for children and youth with special health care needs: a descriptive, multisite study of activities, personnel costs, and outcomes. Pediatrics. 2008;122: e209-e216.

19. David G, Gunnarsson C, Saynisch PA, et al. Do patient-centered medical homes reduce emergency department visits? Health Serv Res [published online August 12, 2014]. doi: 10.1111/1475-6773.12218.

20. Phillips RL, Han M, Petterson SM, et al. Cost, utilization, and quality of care: an evaluation of Illinois' Medicaid primary care case management program. Ann Fam Med. 2014;12:408-417.

21. Shaw RJ, McDuffie JR, Hendrix CC, et al. Effects of nurse-managed protocols in the outpatient management of adults with chronic conditions: a systematic review and meta-analysis. Ann Intern Med. 2014;161:113-121.

22. Hebert R, Durand PJ, Dubuc N, et al. Frail elderly patients. New model for integrated service delivery. Can Fam Physician. 2003;49: 992-997.

23. Dorr DA, Wilcox AB, Brunker CP, et al. The effect of technology supported, multidisease care management on the mortality and hospitalization of seniors. J Am Geriatr Soc. 2008;56:2195-2202.

24. Friedberg MW, Schneider EC, Rosenthal MB, et al. Association between participation in a multipayer medical home intervention and 
changes in quality, utilization, and costs of care. JAMA. 2014;311: 815-825.

25. Hebert PL, Liu CF, Wong ES, et al. Patient-centered medical home initiative produced modest economic results for Veterans Health Administration, 2010-12. Health Aff (Millwood). 2014;33: 980-987.

26. Allison MA, Crane LA, Beaty BL, et al. School-based health centers: improving access and quality of care for low-income adolescents. Pediatrics. 2007;120:e887-e894.

27. Brito A, Grant R, Overholt S, et al. The enhanced medical home: the pediatric standard of care for medically underserved children. Adv Pediatr. 2008;55:9-28.

28. Redlener I, Grant R, Krol DM. Beyond primary care: ensuring access to subspecialists, special services, and health care systems for medically underserved children. Adv Pediatr. 2005;52:9-22.

29. O'Leary ST, Lee M, Federico S, et al. School-based health centers as patient-centered medical homes. Pediatrics. 2014;134:957-964.

30. Brito A, Khaw AJ, Campa G, et al. Bridging mental health and medical care in underserved pediatric populations: three integrative models. Adv Pediatr. 2010;57:295-313.

31. Lynch S, Wood J, Livingood W, et al. Feasibility of shelter-based mental health screening for homeless children. Public Health Rep. 2015; 130:43-47.

32. Garg A, Jack B, Zuckerman B. Addressing the social determinants of health within the patient-centered medical home: lessons from pediatrics. JAMA. 2013;309:2001-2002.

33. Messeri PA, Abramson DM, Aidala AA, et al. The impact of ancillary HIV services on engagement in medical care in New York City. AIDS Care. 2002;14:S15-S29.

34. Campbell F, Conti G, Heckman JJ, et al. Early childhood investments boost adult health. Science. 2014;343:1478-1485.

35. Krol DM, Redlener M, Shapiro A, et al. A mobile medical care approach targeting underserved populations in post-Hurricane Katrina Mississippi. J Health Care Poor Underserved. 2007;18:331-340.

36. Rath B, Donato J, Duggan A, et al. Adverse health outcomes after Hurricane Katrina among children and adolescents with chronic conditions. J Health Care Poor Underserved. 2007;18:405-417.

37. Ridenour ML, Cummings KJ, Sinclair J, et al. Displacement of the underserved: Medical needs of Hurricane Katrina evacuees in West Virginia. J Health Care Poor Underserved. 2007;18:369-381.

38. Madrid PA, Sinclair H, Bankston AQ, et al. Building integrated mental health and medical programs for vulnerable populations post-disaster: connecting children and families to a medical home. Prehosp Disaster Med. 2008;23:314-321.

39. Johnson HL, Gaskins SW, Seibert DC. Clinical skill and knowledge requirements of health care providers caring for children in disaster, humanitarian, and civic assistance operations: an integrative review of the literature. Prehosp Disaster Med. 2013;28:61-68.

40. Abramson DM, Park YS, Stehling-Ariza T, et al. Children as bellwethers of recovery: dysfunctional systems and the effects of parents, households, and neighborhoods on serious emotional disturbance in children after Hurricane Katrina. Disaster Med Public Health Prep. 2010;4: S17-S27.

41. Arrieta MI, Foreman RD, Crook ED, et al. Providing continuity of care for chronic diseases in the aftermath of Katrina: from field experience to policy recommendations. Disaster Med Public Health Prep. 2009;3: 174-182.

42. Davis JR, Wilson S, Brock-Martin A, et al. The impact of disasters on populations with health and health care disparities. Disaster Med Public Health Prep. 2010;4:30-38.

43. Shapiro A, Seim L, Christensen RC, et al. Providing primary care to underserved children after a disaster: a national organization response. Pediatrics. 2006;117:S412-S415.

44. Kanter RK, Abramson DM. School interventions after the Joplin tornado. Prehosp Disaster Med. 2014;29:214-217.

45. Federal Immediate Disaster Case Management Concept of Operations. Washington, DC: Administration for Children and Families, Office of
Human Services Emergency Preparedness and Response, US Department of Health and Human Services. https://www.acf.hhs.gov/sites/default/ files/ohsepr/immediate_dcm_concept_of_operations_conops_october_2012_ 508_compliant.pdf. Published October 2012. Accessed July 8, 2013.

46. Disaster Case Management Guidelines. National Voluntary Organizations Active in Disasters. http://www.nvoad.org/wp-content/ uploads/dlm_uploads/2014/04/dcm_guidelines__ffinal___2012_-_feb.pdf. Accessed May 27, 2015.

47. Acosta J, Chandra A, Feeney KC. Navigating the road to recovery: assessment of the coordination, communication, and financing of the Disaster Case Management Pilot in Louisiana. RAND Corporation. http://www.rand.org/pubs/research_briefs/RB9544/index1.html. Published 2010. Accessed July 8, 2013.

48. FEMA Funds Disaster Case Management Program in Missouri. Federal Emergency Management Agency. http://www.fema.gov/news-release/ 2011/12/08/fema-funds-disaster-case-management-program-missouri. Published December 8, 2011. Accessed July 8, 2013.

49. FEMA-funded Disaster Case Management. Serve Alabama. http://www. servealabama.gov/disastercasemanagement. Accessed July 8, 2013.

50. Bame SI, Parker K, Lee JY, et al. Monitoring unmet needs: using 2-1-1 during natural disasters. Am J Prev Med. 2012;43(6 suppl 5): S435-S442.

51. Hurricane Sandy - Public Health Situation Updates. US Department of Health \& Human Services: Assistant Secretary for Preparedness and Response. http://www.phe.gov/newsroom/Pages/situpdates.aspx. Published December 4, 2012. Accessed July 9, 2013.

52. Rittenhouse DR, Schmidt LA, Wu KJ, Wiley J. The post-Katrina conversion of clinics in New Orleans to medical homes shows change is possible, but hard to sustain. Health Aff (Millwood). 2012;31:1729-1738.

53. Rittenhouse DR, Schmidt LA, Wu KJ, Wiley J. Incentivizing primary care providers to innovate: building medical homes in the post-Katrina New Orleans safety net. Health Serv Res [published online June 26, 2013]. doi: 10.1111/1475-6773.

54. Dawsey J, Campbell D, Cyr K. Rebuilding a community health center following a natural disaster. Health Aff (Millwood). 2007;26:644-650.

55. Carlton PK, Bringle D. Business continuity after catastrophic medical events: the Joplin medical business continuity report. Am J Disaster Med. 2012;7:321-331.

56. The impact of Hurricane Katrina on physician practices and health care provision in Gulf Coast Mississippi. Mississippi State Department of Health. http://msdh.ms.gov/msdhsite/index.cfm/29,3717,236,324,pdf/ KatrinaHealthcareImpact.pdf. Published 2009. Accessed July 8, 2013.

57. Needle S. Pediatric private practice after Hurricane Katrina: proposal for recovery. Pediatrics. 2008;122:836-842.

58. Meredith LS, Eisenman DP, Tanielian MA, et al. Prioritizing "psychological" consequences for disaster preparedness and response: a framework for addressing the emotional, behavioral, and cognitive effects of patient surge in large-scale disasters. Disaster Med Pub Health Prep. 2011;5:73-80.

59. Croy C, Smail C, Horsley E. Preparing for and recovering from a natural disaster. Fam Pract Manag. 2012;19:15-18.

60. Runkle JD, Zhang H, Karmaus W, et al. Prediction of unmet primary care needs for the medically vulnerable post-disaster: an interrupted time-series analysis of health system responses. Int J Environ Res Public Health. 2012;9:3384-3397.

61. Berry S, Soltau E, Richmond NE, et al. Care coordination in a medical home in post-Katrina New Orleans: lessons learned. Matern Child Health J. 2011;15:782-793.

62. National Commission on Children and Disasters. 2010 Report to the President and Congress. AHRQ Publication No. 10-M037. Rockville, Md: Agency for Healthcare Research and Quality; October 2010: 75-77.

63. Agency for Healthcare Research and Quality. Allocation of Scarce Resources During Mass Casualty Events. AHRQ Evidence Report No. 207. Rockville, Md: Agency for Healthcare Research and Quality; 2012.

64. Svendsen ER, Whittle NC, Sanders L, et al. GRACE: public health recovery methods following an environmental disaster. Arch Environ Occup Health. 2010;65:77-85. 
65. Jan S, Lurie N. Disaster resilience and people with functional needs. N Engl J Med. 2012;367:2272-2273.

66. Chen AY, Schrager SM, Mangione-Smith R. Quality measures for primary care of complex pediatric patients. Pediatrics. 2012;129:433-445.

67. Cohen E, Lacombe-Duncan A, Spalding K, et al. Integrated complex care coordination for children with medical complexity: a mixedmethods evaluation of tertiary care-community collaboration. BMC Health Serv Res. 2012;12:366.
68. Mack D, Rust GS, Baltrus P, et al. Using appendiceal perforation rates to measure impact of a disaster on healthcare system effectiveness. South Med J. 2013;106:82-88.

69. Kansagara D, Tuepker A, Joos S, et al. Getting performance metrics right: a qualitative study of staff experiences implemeneting and measuring practice transformation. J Gen Intern Med. 2014;29(suppl 2):S607-S613.

70. Lurie N, Manolio T, Patterson AP, et al. Research as part of public health emergency response. N Engl J Med. 2013;368:1251. 